\title{
Virulence of Aerial Conidia of Beauveria bassiana Produced under LED Light to Ctenocephalides felis (Cat Flea)
}

\author{
Sarayut Pittarate, ${ }^{1}$ Malee Thungrabeab, ${ }^{2}$ Supamit Mekchay, ${ }^{3}$ and Patcharin Krutmuang $\mathbb{D}^{1}$ \\ ${ }^{1}$ Department of Entomology and Plant Pathology, Faculty of Agriculture, Chiang Mai University, Chiang Mai 50200, Thailand \\ ${ }^{2}$ Agricultural Technology Research Institute, Rajamangala University of Technology Lanna, Lampang 52000, Thailand \\ ${ }^{3}$ Department of Animal and Aquatic Sciences, Faculty of Agriculture, Chiang Mai University, Chiang Mai 50200, Thailand \\ Correspondence should be addressed to Patcharin Krutmuang; patcharink26@gmail.com
}

Received 26 April 2018; Revised 15 August 2018; Accepted 24 September 2018; Published 1 November 2018

Academic Editor: Panagiotis Karanis

Copyright (C) 2018 Sarayut Pittarate et al. This is an open access article distributed under the Creative Commons Attribution License, which permits unrestricted use, distribution, and reproduction in any medium, provided the original work is properly cited.

\begin{abstract}
Ctenocephalides felis is an ectoparasitic flea species commonly found on dogs and cats. The current study verified the in vitro virulence of conidia of the entomopathogenic fungus Beauveria bassiana produced under different color LED light (red, blue, purple, green, yellow, and white) to adults of $C$. felis. The fungal isolates were cultivated on malt extract agar (MEA). Bioassay treatments used aerial conidia in test tubes. Adult fleas were obtained from a house cat in Chiang Mai province, Thailand. The experiments were composed of one control and eleven treatment groups. All of the treatments with B. bassiana conidia caused adult mortality after an exposure of $12 \mathrm{~h}$. Among the conditions used in this study, B. bassiana cultured under red LED and fluorescent light were the most effective in causing mortality $(100 \%)$ in adult fleas after $36 \mathrm{~h}$. The experimental results indicate that these aerial conidia of $B$. bassiana have promising potential for use in control of $C$. felis adult stages.
\end{abstract}

\section{Introduction}

The dog and cat fleas (Insecta: Siphonaptera), Ctenocephalides canis (Curtis), and Ctenocephalides felis felis (Bouché) are small, laterally flattened, wingless, and highly specialized insects. They are very important obligate hematophagous ectoparasites and have worldwide distribution $[1,2]$. The adult flea lives on the host and the female lays eggs which fall from the animal and develop into larvae in the environment [3-5]. Both adult males and females are blood feeding and cause the immunoallergic skin affliction which is responsible for flea allergy dermatitis (FAD) of mammals and birds $[6,7]$. Fleas can also be competent vectors for numerous pathogens, including zoonotic such as Rickettsia typhi (murine typhus), Bartonella henselae ("cat scratch disease" in humans), and Yersinia pestis (plague) and act as the intermediate host of the tapeworm species Dipylidium caninum $[5,8-10]$. Traditional management of adult flea infestations on animals, during the past $15 \mathrm{y}$ is by topical and oral applications of insecticides such as fipronil, imidacloprid, selamectin, and most recently by insect growth regulators (IGRs) such as lufenuron [2, 9, 11-16]. Recent studies show that these therapies eliminate the need to treat indoor and outdoor environments, and their use markedly reduces the severity and prevalence of flea infestations [1720]. However, control of fleas by synthetic chemicals at present is very deleterious to the environment, pets, and pet owners.

Entomopathogenic fungi are microorganisms in nature that have high potential to infect, kill, control, and prevent subsequent reinfestation of many insect pests $[4,10$, 21]. Beauveria bassiana (Balsamo) Vuillemin (Hypocreales: Clavicipitaceae) is one of the most important biological control agents used in insect IPM programs and has been formulated as many commercial products. Moreover, this fungus has a wide insect-host range and has been one of the most widely studied $[22,23]$. B. bassiana produces conidia for dispersal, transmission, and infection of other insect pests. This approach is safe for the environment pets and pet owners. The objective of this study was to evaluate the virulence of aerial conidia of $B$. bassiana produced under different colors of LED light to adult cat fleas. 
TABLE 1: The ability of aerial conidia of B. bassiana isolate BCMU4 produced under LED lights to control Ctenocephalides felis.

\begin{tabular}{|c|c|c|c|c|}
\hline \multirow{2}{*}{ Fungus conditions } & \multicolumn{4}{|c|}{ Adult mortality (\%) at infestation day } \\
\hline & $12 \mathrm{~h}$ & $24 \mathrm{~h}$ & $36 \mathrm{~h}$ & $48 \mathrm{~h}$ \\
\hline B. bassiana $+\mathrm{red}$ & $27 a^{*}$ & $93 a$ & $100 \mathrm{a}$ & 100 \\
\hline B. bassiana + blue & $25 \mathrm{a}$ & $87 \mathrm{bc}$ & $93 b$ & 100 \\
\hline B. bassiana + purple & $23 a$ & $89 \mathrm{ab}$ & $91 b c$ & 100 \\
\hline B. bassiana + green & $11 \mathrm{bc}$ & $84 c d$ & $89 \mathrm{~cd}$ & 100 \\
\hline B. bassiana + yellow & $13 \mathrm{bc}$ & $80 \mathrm{de}$ & $89 \mathrm{~cd}$ & 100 \\
\hline B. bassiana + white & $10 \mathrm{~cd}$ & $83 c d$ & $87 \mathrm{~d}$ & 100 \\
\hline B. bassiana + fluorescent & $15 b$ & $86 \mathrm{bc}$ & $100 \mathrm{a}$ & 100 \\
\hline B. bassiana + dark & $6 \mathrm{~d}$ & $78 \mathrm{e}$ & $86 \mathrm{~d}$ & 100 \\
\hline M. anisopliae 4849 & $25 \mathrm{a}$ & $92 \mathrm{a}$ & $100 \mathrm{a}$ & 100 \\
\hline M. anisopliae $2 \mathrm{MG}$ & $26 \mathrm{a}$ & $92 \mathrm{a}$ & $99 \mathrm{a}$ & 100 \\
\hline Control group & $0 \mathrm{e}$ & of & $0 \mathrm{e}$ & 0 \\
\hline LSD $(0.05 \%)$ & 2.2361 & 2.0207 & 1.7795 & - \\
\hline $\mathrm{CV}$ & 23.44 & 4.44 & 3.61 & - \\
\hline
\end{tabular}

${ }^{*}$ Means followed by the same letter in the same row in each parameter are not significantly different by LSD $(\mathrm{P}<0.05)$. Means calculated from five replications. Experiments were kept at $27 \pm 1^{\circ} \mathrm{C}$ and relative humidity $(\mathrm{RH}) \geq 80 \%$.

\section{Materials and Methods}

2.1. Fungus Strain and Growth Conditions. B. bassiana isolate BCMU4 was obtained from the Rajamangala University of Technology Lanna Collection of Entomopathogenic Fungal Cultures, Lampang. BCMU4 was originally isolated from Nilaparvata lugens (Stål) (Brown plant hopper) [Hemiptera: Delphacidae] in Pitsanulok, Thailand. Stock cultures were maintained in test tubes on slants of MEA medium (malt extract $4 \%$ soybean peptone $1 \%$ and agar $1.5 \%)$ at $25 \pm 1^{\circ} \mathrm{C}$ with a photoperiod of $12: 12 \mathrm{~h}$ (dark : light). B. bassiana was screened for stimulation of conidiation with six colors of LED light (red, blue, purple, green, yellow, white) and under fluorescent light and darkness. After $1 \mathrm{~h}$ exposure to the light treatments, cultures were kept in the dark at $27 \pm 1^{\circ} \mathrm{C}$ and relative humidity $(\mathrm{RH}) \geq 80 \%$ for $15 \mathrm{~d}$. This study used aerial conidia produced by transferring one plug ( $5 \mathrm{~mm}$. diam.) from the growing edge of a colony to each test tube. Conidia were suspended in a $0.01 \%$ aqueous solution of Tween 80 and quantified by haemocytometer.

2.2. Flea Strain. Adult fleas used in this study were the laboratory strain that has been maintained at the Insect Pathology Laboratory, Department of Entomology and Plant Pathology, Faculty of Agriculture, Chiang Mai University, Thailand. This colony originated from a wild strain taken from a house cat in Chiang Mai area and has been maintained on cats under laboratory conditions. Fleas were removed from cats via combining and counted in a test tube for every treatment (11 tr.) which was done for 5 replications. The strain has not been pressured with any insecticides since then. Bioassay treatments using 20 live fleas per one test tube were kept at room temperature for $1-2 \mathrm{~h}$ and were treated with one plug $(0.5 \mathrm{~mm}$. diam.) of $B$. bassiana in each test tube, incubated at $27 \pm 1^{\circ} \mathrm{C}$, and mortality was checked every 12 h. The experiment had two control groups: pure agar and Metarhizium anisopliae. Mean mortality time and $\mathrm{LC}_{50}$ were calculated and statistical analysis used one-way ANOVA and significance between treatments was tested with the LSD method $(P<0.05)$.

\section{Results}

Previous studies have shown that different color LED light has great potential to stimulate $B$. bassiana conidial production with a high virulence to pests. In the current study, the mortality of Ctenocephalides sp. observed in treatments 1-11 was time-dependent (Table 1). Adult fleas treated with one plug (0.5 mm. diam.) of the fungus grown on MEA, B. bassiana $+\left[\operatorname{red}\left(0.21 \times 10^{8}\right.\right.$ conidia $\left./ \mathrm{ml}\right)$, blue $\left(0.03 \times 10^{8}\right.$ conidia $\left./ \mathrm{ml}\right)$, purple $\left(0.06 \times 10^{8}\right.$ conidia $\left./ \mathrm{ml}\right)$, green $\left(0.11 \times 10^{8}\right.$ conidia $\left./ \mathrm{ml}\right)$, yellow $\left(0.07 \times 10^{8}\right.$ conidia $\left./ \mathrm{ml}\right)$, white $\operatorname{LED}\left(0.05 \times 10^{8}\right.$ coni$\mathrm{dia} / \mathrm{ml})]$, B. bassiana + (fluorescent $\left(0.09 \times 10^{8}\right.$ conidia $\left./ \mathrm{ml}\right)$, dark $\left(0.09 \times 10^{8}\right.$ conidia $\left.\left./ \mathrm{ml}\right)\right)$, and two isolates of $M$. anisopliae (4849 $\left(0.04 \times 10^{7}\right.$ conidia $\left./ \mathrm{ml}\right), 2 \mathrm{MG}\left(0.13 \times 10^{8}\right.$ conidia $\left.\left./ \mathrm{ml}\right)\right)$ had significantly different mortalities at $12 \mathrm{~h}$ after treatment. The results revealed that the cumulative mortalities of adults at $12 \mathrm{~h}$ ranged between 6 and 27 percent. After $24 \mathrm{~h}$, all of fungal treatments showed a cumulative flea mortality of more than 75 percent. During the same period, B. bassiana + (red, purple) and two isolates of $M$. anisopliae (4849,2MG) showed the highest cumulative mortalities of $93,89,92$, and $92 \%$, respectively, and were not significantly different, while $100 \%$ mortality was reached in the treatments B. bassiana + (red, fluorescent) and M. anisopliae (4849) after $36 \mathrm{~h}$ (Table 1). All fleas treated with entomopathogenic fungi were killed within $48 \mathrm{~h}$ after exposure. No mortality was observed in the control group. After dead host fungal will formation mycelial outgrowth from insect cadaver and production of new conidia (Figure 1). 
a

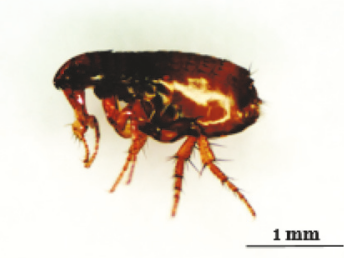

(a) b

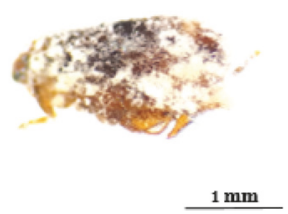

(b) c

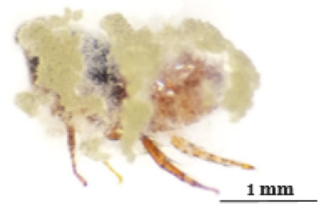

(c)

Figure 1: Cumulative mortalities of Ctenocephalides sp. male and female adults after exposure to fungal aerial conidia. (a) Healthy adult of Ctenocephalides sp., (b) adults of Ctenocephalides sp. (72 h) after death caused by B. bassiana isolate BCMU4, and (c) Adults of Ctenocephalides sp. $(72 \mathrm{~h}$ ) after death caused by $M$. anisopliae All the scales bars are $1 \mathrm{~mm}$.

\section{Discussion}

To the best of our knowledge, the work of seeking efficient entomopathogenic fungi against Ctenocephalides sp. was also only undertaken by De-Melo et al. $[1,21,24]$. B. bassiana has shown pathogenicity as a biological control agent for different arthropod species and it is commercially available as various mycoinsecticides $[1,10,21]$. In our study, aerial conidia of $B$. bassiana produced under LED light start killing fleas within $12 \mathrm{~h}$ after treatment administration [21]. Moreover, $B$. bassiana had a cumulative flea mortality of $100 \%$ in $36-48 \mathrm{~h}$ as short time similar some synthetic chemicals $[2,7,9,14,23]$. In general, for flea control in dogs and cats garden or backyard areas are treated with insecticides in an attempt to control flea infestations. However, such applications of insecticides are often poorly targeted. Hence, entomopathogenic agents have benefits in terms of effectiveness against flea infestations. It is difficult for fleas to become resistant to entomopathogenic fungi. But this insect can readily develop resistance to chemical insecticides $[17,25]$. Similarly, in a study conducted by Coles and Dryden [22] it was reported that control of fleas with entomopathogenic fungi can be conducted safely in terms of positive benefits for the environment, pets, and pet owners [10, 19]. Previous research [26] showed that different isolates of $M$. anisopliae had different effects on insect pests. So, identification, application and screening of different fungal isolates in bioassays may provide promising biopesticides. Our study screened both B. bassiana and $M$. anisopliae with activity against adult fleas. The current research showed that growth of $B$. bassiana under LED lights enhanced production of conidia that resulted in $100 \%$ overall flea mortality. Future research will examine the ovicidal and larvicidal capacity of this entomopathogenic fungus. In the future such entomopathogenic fungi could be developed as bioinsecticides for practical use in pet care products like Chaingard ${ }^{\circledR}$ pets powder. The evidence presented here indicates that both $B$. bassiana and $M$. anisopliae have a high level of adulticidal activity, and potential for inclusion in flea management systems.

\section{Conclusions}

A previous study showed the efficacy of flea control by using aerial conidia of $B$. bassiana produced under difference colors of LED light was relatively high ranging from 78 to 100 percent and rapidly occurred from 24 to $36 \mathrm{~h}$ after exposure. Comparisons of conidia of $B$. bassiana produced under different colors of LED light to enhance their virulence and efficacy were obtained from the experiments. Conidia of $B$. bassiana produced under different colors of LED light caused infection which involves integument penetration at 12 $\mathrm{h}$ and total colonization of the insect at $48 \mathrm{~h}$ after exposure. Therefore, these results indicate that $B$. bassiana culture under LED light has great potential as a candidate for biological control of Ctenocephalides sp. adult stages. The potential of this entomopathogenic fungus for controlling fleas needs continued study, and the research should be expanded to include other ectoparasites of dogs and cats.

\section{Abbreviations \\ LED: Light emitting diodes \\ MEA: Malt extract agar.}

\section{Data Availability}

The data used to support the findings of this study are included within the article.

\section{Conflicts of Interest}

The authors declare that there are no conflicts of interest.

\section{Acknowledgments}

The authors would like to thank Professor Dr. Robert J. McGovern for his helpful comments to improve the quality of the paper. This work is sponsored by the Agricultural Research Development Agency (Public Organization). We would like to thank the Department of Entomology and Plant Pathology, Faculty of Agriculture, Chiang Mai University, Thailand, for their facilities and equipment.

\section{References}

[1] A. Sangvaranond, "Studies on ectoparasites of domesticated dogs and cats in Thailand," Kasetsart Veterinarians. 
[2] F. V. Adriano, W. R. Everett, S. J. Holzmer et al., "Efficacy of a new spot-on formulation of selamectin plus sarolaner for cats against adult Ctenocephalides felis, flea egg production and adult flea emergence," Veterinary Parasitology, vol. 238, pp. S22S26, 2017.

[3] K. R. Michael, "Advances in the control of Ctenocephalides felis (cat flea) on cats and dogs," TRENDS in Parasitology, vol. 21, no. 5, pp. 232-236, 2005.

[4] M. Li, H. Lin, S. Li et al., "Virulence of entomopathogenic fungi to adults and eggs of Nilaparvata lugens Stal (Homoptera: Delphacidae," African Journal of Agricultural Research, vol. 7, no. 14, pp. 2183-2190, 2012.

[5] O. M. Amin, "The fleas (Siphonaptera) of Egypt: distribution and seasonal dynamics of fleas infesting dogs in the Nile valley and delta.," Journal of Medical Entomology, vol. 3, no. 3, pp. 293298, 1966.

[6] I. Bitam, K. Dittmar, P. Parola, M. F. Whiting, and D. Raoult, "Fleas and flea-borne diseases," International Journal of Infectious Diseases, vol. 14, no. 8, pp. e667-e676, 2010.

[7] M. W. Dryden and M. K. Rust, "The cat flea: biology, ecology and control," Veterinary Parasitology, vol. 52, no. 1-2, pp. 1-19, 1994.

[8] C. Cruz-Vazquez, E. C. Gamez, M. P. Fernandez, and M. R. Parra, "Seasonal occurrence of Ctenocephalides felis felis and Ctenocephalides canis (Siphonaptera:Pulicidae) infesting dogs and cats in an urban area in Cuernavaca, Mexico," Journal of Medical Entomology, vol. 38, no. 1, pp. 111-113, 2001.

[9] C. McCoy, A. B. Broce, and M. W. Dryden, "Flea blood feeding patterns in cats treated with oral nitenpyram and the topical insecticides imidacloprid, fipronil and selamectin," Veterinary Parasitology, vol. 156, no. 3-4, pp. 293-301, 2008.

[10] A. K. Charnley and S. A. Collins, "Entomopathogenic fungi and their role in pest control," in The Mycota IV: Environmental and Microbial Relationships, C. P. Kubicek and I. S. Druzhinina, Eds., pp. 159-187, Springer-Verlag, Berlin, Germany, 2nd edition, 2007.

[11] B. A. Moser, P. G. Koehler, and R. S. Patterson, "Effect of methoprene and diflubenzuron on larval development of the cat flea (Siphonaptera: Pulicidae).," Journal of Economic Entomology, vol. 85, no. 1, pp. 112-116, 1992.

[12] D. R. Young, P. C. Jeannin, and A. Boeckh, "Efficacy of fipronil/(S)-methoprene combination spot-on for dogs against shed eggs, emerging and existing adult cat fleas (Ctenocephalides felis, Bouché)," Veterinary Parasitology, vol. 125, no. 3-4, pp. 397-407, 2004.

[13] E. Bouhsira, S. S. Yoon, M. Roques et al., "Efficacy of fipronil, amitraz and (S)-methoprene combination spot-on for dogs against adult dog fleas (Ctenocephalides canis, Curtis, 1826)," Veterinary Parasitology, vol. 179, no. 4, pp. 351-353, 2011.

[14] K. G. Palma, S. M. Meola, and R. W. Meola, "Mode of action of pyriproxyfen and methoprene on eggs of Ctenocephalides felis (Siphonaptera: Pulicidae).," Journal of Medical Entomology, vol. 30, no. 2, pp. 421-426, 1993.

[15] R. Meola, S. Pullen, and S. Meola, “Toxicity and Histopathology of the Growth Regulator Pyriproxyfen to Adults and Eggs of the Cat Flea (Siphonaptera: Pulicidae)," Journal of Medical Entomology, vol. 33, no. 4, pp. 670-679, 1996.

[16] T. L. McTier, D. J. Shanks, A. D. Jernigan et al., "Evaluation of the effects of selamectin against adult and immature stages of fleas (Ctenocephalides felis felis) on dogs and cats," Veterinary Parasitology, vol. 91, no. 3-4, pp. 201-212, 2000.
[17] M. Dryden, D. Carithers, A. McBride et al., "A comparison of flea control measurement methods for tracking flea populations in highly infested private residences in Tampa fl, following topical treatment of pets with FRONTLINE $^{\circledR}$ (Fipronil/(S)Methoprene)," International Journal of Applied Research in Veterinary Medicine, vol. 9, no. 4, pp. 356-367, 2011.

[18] T. B. Coles and M. W. Dryden, "Insecticide/acaricide resistance in fleas and ticks infesting dogs and cats," Parasites \& Vectors, vol. 7, no. 1, article 8, 2014.

[19] T. Geurden, C. Becskei, R. Farkas, D. Lin, and D. Rugg, "Efficacy and safety of a new spot-on formulation of selamectin plus sarolaner in the treatment of naturally occurring flea and tick infestations in cats presented as veterinary patients in Europe," Veterinary Parasitology, vol. 238, pp. S12-S17, 2017.

[20] V. H. Guerrini and C. M. Kriticos, "Effects of azadirachtin on Ctenocephalides felis in the dog and the cat," Veterinary Parasitology, vol. 74, no. 2-4, pp. 289-297, 1998.

[21] D. R. De Melo, É. K. K. Fernandes, G. L. Da Costa, F. B. Scott, and V. R. E. P. Bittencourt, "Virulence of Metarhizium anisopliae and Beauveria bassiana to Ctenocephalides felis felis," Annals of the New York Academy of Sciences, vol. 1149, pp. 388390, 2008.

[22] A. V. Reddy, R. S. Devi, S. Dhurua et al., "Study on the efficacy of some entomogenous fungi against brown plant hopper, Nilaparvata lugens Stal in irrigated rice," Journal of Biopesticides, vol. 6, no. 2, pp. 139-143, 2013.

[23] C. A. Valero-Jiménez, H. Wiegers, B. J. Zwaan, C. J. Koenraadt, and J. A. van Kan, "Genes involved in virulence of the entomopathogenic fungus Beauveria bassiana," Journal of Invertebrate Pathology, vol. 133, pp. 41-49, 2016.

[24] M. K. Rust, "Insecticide resistance in fleas," Insects, vol. 7, no. 1, 2016.

[25] R. L. Bossard, N. C. Hinkle, and M. K. Rust, "Review of Insecticide Resistance in Cat Fleas (Siphonaptera: Pulicidae)," Journal of Medical Entomology, vol. 35, no. 4, pp. 415-422, 1998.

[26] N. Sedighi, H. Abbasipour, H. Askary, A. S. Gorjan, and J. Karimi, "Pathogenicity of the entomopathogenic fungus Metarhizium anisopliae var. major on different stages of the sunn pest Eurygaster integriceps," Journal of Insect Science, vol. 13, article no. 150, 2013. 


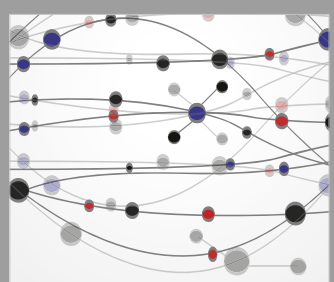

The Scientific World Journal
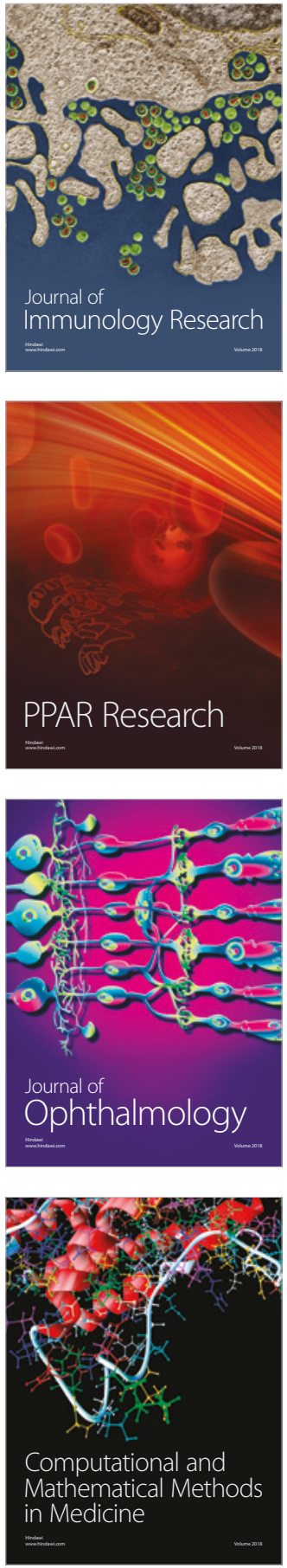

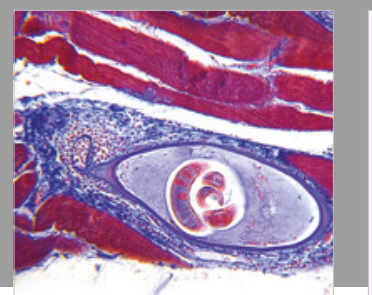

Gastroenterology Research and Practice

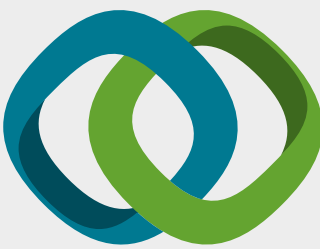

\section{Hindawi}

Submit your manuscripts at

www.hindawi.com
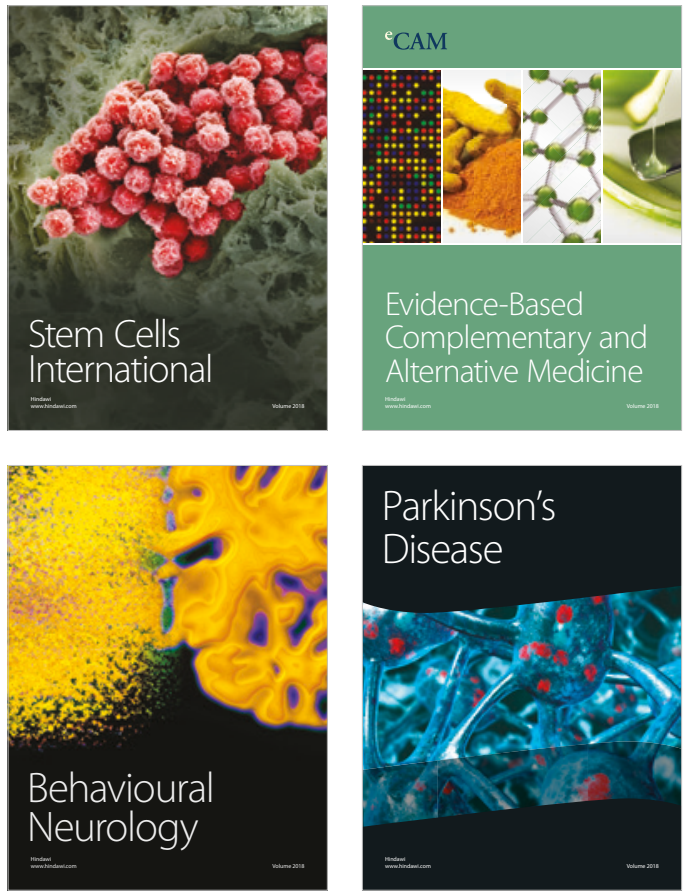

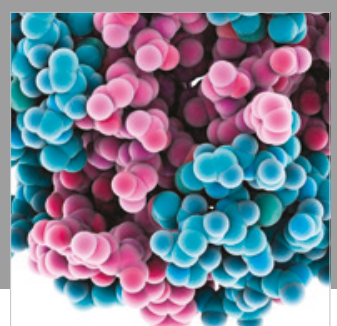

ournal of

Diabetes Research

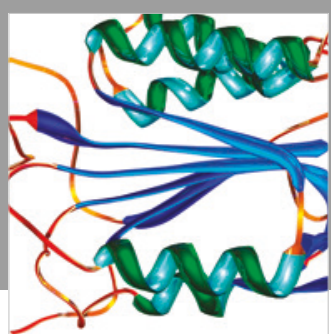

Disease Markers
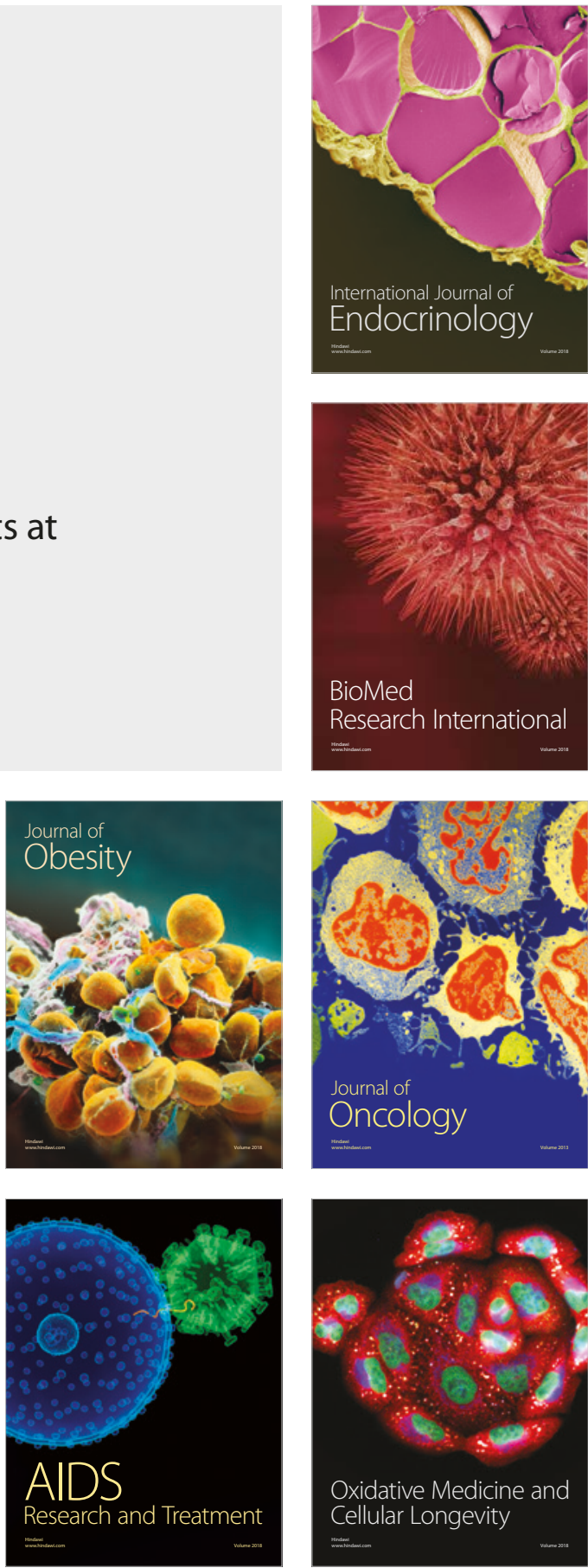